\title{
PERANCANGAN PROTOTYPE MESIN PEMBERSIH KABEL TRANSMISI LISTRIK BERBASIS INTERNET
}

\author{
Shintya Adhe Putri ${ }^{1}$, A.Asni B ${ }^{2}$, Aswadul Fitri ${ }^{3}$ \\ ${ }^{1,2,3}$ Teknik Elektro,Fakultas Teknologi Industri Universitas Balikpapan \\ Jln. Pupuk Raya Gn. Bahagia Balikpapan 76114 INDONESIA \\ Email : Shintyaadhe36@gmail.com
}

\begin{abstract}
This research on the tittle " DESIGNING PROTOTYPE CLEANING MACHINE IN INTERNET- BASED ELECTRIC TRANSMISSION CABLE " this theses to eassly cleaning lines transmission cable from the dirt of lines cable transmission used by Arduino UNO, as a first component, L298N as a Driver Motor Electric fuction to movers motor dynamo. This tools have a cleaning can cleaning at line cable transmission with the mover cutting motor dynamo, that tools cutiing direct clockwise and the opporside.

Based on the tool teste of cutting materials made from arcylyric its not efisiens on cutting all the hard dirt concern at transmission cable. While of the materials made from grinda is more efisien in cutting and concern hard dirt at transmission cable
\end{abstract}

Keywords : ESP 8266, Aduino, L298N, Battery Li-Po.

Intisari- Penelitian ini berjudul "PERANCANGAN PROTOTYPE MESIN PEMBERSIH KABEL TRANSMISI LISTRIK BERBASIS INTERNET" yang bertujuan untuk mempermudah membersihkan jalur kabel transmisi listrik dari kotoran yang terdapat dijalur kabel transmisi yang digunakan adalah Arduino UNO sebagai komponen utama, L298N sebagai Driver Motor elektrik yang berfungsi sebagai media penggerak motor Dinamo. Alat ini dapat membersihkan kotoran-kotoran yang terdapat dijalur kabel transmisi listrik dengan pemotong yang digerakkan dengan motor dinamo, alat tersebut memotong searah jarum jam dan sebaliknya. Berdasarkan hasil uji coba pada alat, bahan pemotong yang terbuat dari Arcylic kurang efisien dalam memotong kotoran - kotoran keras yang menyangkut pada kabel transmisi listrik. Sedangkan pada bahan yang terbuat dari grinda besi lebih efisien dalam memotong kotoran yang menyangkut pada kabel transmisi listrik.

Kata Kunci- ESP 8266,Arduino, L298N, Battery Li-Po.

\section{Pendahuluan}

Perkembangan Teknologi begitu pesat membuat kebutuhan teknologi semakin bertambah. Manusia cenderung menggunakan teknologi untuk menunjang kinerja dan kebutuhan. Perkembangan teknologi berimbas pada penggunaan alat bantu untuk menjadikan pekerjaan lebih ringan. Menggunakan teknologi pula seseorang dapat melakukan pekerjaan dengan cepat dan baik, salah satunya adalah robot yang dapat membersihkan sampah - sampah atau benda - benda yang tidak digunakan.

Banyaknya gangguan - gangguan yang terjadi pada jalur transmisi listrik atau gangguan pada kabel seperti korsleting dan gangguan medan listrik yang terjadi apabila kabel transmisi listrik tidak dibersihkan, benda - benda yang sering merusak atau menggangu kabel transmisi listrik antar lain berupa benang layangan, ranting pohon, dan lain sebagainya.
Dengan masalah tersebut, perancang ingin membuat sebuah kreasi dengan membuat alat mesin pengaman kabel transmisi listrik. Cara kerja alat yang akan dibuat adalah alat akan mendeteksi kotoran yang terdapat pada kabel transmisi dan akan membersihkan dengan cara memotong kotoran yang mengganggu tersebut. Alat ini dirancang untuk memudahkan pemeliharaan kabel transmisi listrik seperti membersihkan benang layangan, ranting pohon dan lain sebagainya.

\section{Tinjauan PuSaka}

\subsection{Penelitian Terdahulu}

Perancangan Prototype Mesin Pembersih Kabel Transmisi Listrik ini diharapkan mampu memberikan kemudahan bagi para petugas P2TL untuk pemeliharaan kabel transmisi listrik. Dimana ketika alat ini diterapkan, maka petugas P2TL tidak harus repot atau mendapatkan resiko ketika membersihkan kabel transmisi listrik. Alat yang akan dibuat menggunakan beberapa komponen, yaitu Driver Motor L298N, Dinamo 700rpm, Arduino UNO, Li-Po Battery 3s. Dalam hal ini, penulis membaca dan memahami literature ilmiah yang sejenis dengan penulis, guna menambah literature penulis dalam melakukan penellitian.

Dalam penelitian yang dilakukan oleh Novi Lestari dari STMIK-MMURA LUBUKLINGGAU Fakultas Teknik Informatika Politeknik Sekayu (TIPS) yang berjudul Pemanfaatan Jaringan Wireless Sebagai Pengendali Robot Penyiram Tanaman Berbasis Mikrokontroler. Hasil dari penellitian yaitu dengan perancangan perangkat keras terdiri dari Mikrokontroler ATMEGA328, Arduino UNO, Modul Wireless 433MHz, Motor DC sebagai pengendali jarak jauh menggunakan computer dan robot peneliti menggunakan module wireless $433 \mathrm{MHz}$ dengan menggunakan frekuensi radio, Driver motor L293D sebagai penggerak yang sudah dilengkapi dengan gearbox agar dapat berputar berlawanan arah jarum jam, battery Li-ion berguna sebagai daya [1].

Didalam penelitian yang dilakukan oleh S.Samsugi, Ardiansyah, Dyan Kastutara dari Universitas Teknorat Indonesia dan Universitas Lampung Fakultas Teknik Informatika dan Ilmu Komputer dengan judul Arduino Uno Modul Wifi ESP8266 Sebagai Media Kendali Jarak Jauh Dengan Antarmuka Berbasis Android. Hasil dari penelitian yaitu dengan perancangan perangkat keras terdiri dari Arduino UNO, Modul Wifi ESP8266, Smartphone, Adaptor 12Volt, Power Supply. Arduino UNO sebagai penghubung sekaligus otak dari alat tersebut, fungsi dari smartphone adalah sebagai pengendali antarmuka lampu dan AC, Modul Wifi ESP8266 menghubungkan atau mengkoneksikan alat dengan android 
atau pengendali dan Powe Supply sebagai daya dari alat tersebut [2].

Penelitian lainnya yang berkaitan adalah Rancang Bangun Pengaman Pintu Otomatis Menggunakan E-KTP Berbasis Mikrokontroler ATMega328. Yang disusun oleh Eko Saputra dan Hari Wibawanto. Hasil dari penelitiannya yaitu menggunakan beberapa alat yang terdiri dari Mikrokontroler ATMega328, E-KTP, Push Button, LCD 16x2, RFID Reader, Relay, dan Selenoid. Fungsi dari RFID reader ialah membaca nomor id dari E-KTP, Mikrokontroler ATMega328 berfungsi sebagai saklar untuk mengaktifkan solenoid dan LCS untuk menampilkan [3].

Penelitian selanjutnya adalah Protype Sistem Telemtri Tinggi MUKA Air dan KONTROL Pintu Air Otomatis Berbasis Mikrokontroler ATMega328P dan ESP8266. Yang disusun oleh Hengki, Boni Pahlanop Lapanporo, Nurhasanah dari Universitas Tanjungpura. Hasil dari penelitian yaitu dengan perancangan perangkat keras terdiri dari Motor Servo, Sensor Ultrasonic, Arduino UNO, ESP8266. Arduino UNO sebagai penghubung sekaligus otak dari alat tersebut fungsi dari motor servo untuk membuka dan menutup pintu air, modul ESP8266 merupakan modul yang digunakan sebagai pengirim data, sensor ultrasonic berfungsi sebagai pengukur ketinggian permukaan air [4].

Penelitian selanjutnya dilakukan oleh Yulia, S.T,M.T, Umi Nur Kholifah dari Universitas Mercu Buana Fakultas Teknik dengan judul Robot Pembersih Lantai Berbasis Arduino Uno Denngan Sensor Ultrasonik. Hasil dari penelitian yaitu dengan perancangan perangkat keras terdiri dari Arduino Uno, Motor Driver L298N, Sensor Ultrasonik, Motor DC, LCD, Relay, Push Button. Arduino Uno sebagai penghubung sekaligus otak dari alat tersebut, LCD berfungsi sebagai penampil text. Sensor Ultrasonik berfungsi sebagai pembaca atau pendetksi gerak sekitar, Motor DC berfungsi sebagai penggerak [5].

\subsection{Driver Motor L298N}

Driver Motor L298N merupakan module driver motor DC yang paling banyak digunakan atau dipakai di dunia elektronika yang difungsikan untuk mengontrol kecepatan serta arah perputaran motor DC. IC L298 merupakan sebuah IC tipe H-bridge yang mampu mengendalikan beban-beban induktif seperti relay, solenoid, motor DC dan motor stepper. Pada IC L298 terdiri dari transistor-transistor logik (TTL) dengan gerbang nand yang berfungsi untuk memudahkan dalam menentukan arah putaran suatu motor de maupun motor stepper. Untuk dipasaran sudah terdapat modul driver motor menggunakan ic 1298 ini, sehingga lebih praktis dalam penggunaannya karena pin I/O nya sudah terpackage dengan rapi dan mudah digunakan. Kelebihan akan modul driver motor L298N ini yaitu dalam hal kepresisian dalam mengontrol motor sehingga motor lebih mudah untuk dikontrol.

\subsection{NODEMCU8266 Versi 3.0}

NodeMCU pada dasarnya adalah pengembangan dari ESP8266 dengan firmware berbasis e-Lua. Pada
NodeMCU dilengkapi dengan micro usb port yang berfungsi untuk pemograman maupun power supply. Selain itu juga pada NodeMCU dilengkapi dengan tombol push button yaitu tombol reset dan flash. NodeMCU menggunakan bahasa pemograman Lua yang merupakan package dari esp8266. Bahasa Lua memiliki logika dan susunan pemograman yang sama dengan c hanya berbeda syntax. Jika menggunakan bahasa Lua maka dapat menggunakan tool Lua loader maupun Lua uploder. Selain dengan bahasa LuaNodeMCU juga support dengan software Arduino IDE dengan melakukan sedikit perubahan board manager pada Arduino IDE.

Sebelum digunakan Board ini harus di Flash terlebih dahulu agar support terhadap tool yang akan digunakan. Jika menggunakan Arduino IDE menggunakan firmware yang cocok yaitu firmware keluaran dari Ai-Thinker yang support AT Command. Untuk penggunaan tool loader Firmware yang digunakan adalah firmware NodeMCU.

\subsection{Battery Li-Po}

Baterai LiPo tidak menggunakan cairan sebagai elektrolit melainkan menggunakan elektrolit polimer kering yang berbentuk seperti lapisan plastik film tipis. Lapisan film ini disusun berlapis-lapis diantara anoda dan katoda yang mengakibatkan pertukaran ion.

Dengan metode ini baterai LiPo dapat dibuat dalam berbagai bentuk dan ukuran. Diluar dari kelebihan arsitektur baterai LiPo, terdapat juga kekurangan yaitu lemahnya aliran pertukaran ion yang terjadi melalui elektrolit polimer kering. Hal ini menyebabkan penurunan pada charging dan discharging rate. Masalah ini sebenarnya bisa diatasi dengan memanaskan baterai sehingga menyebabkan pertukaran ion menjadi lebih cepat, namun metode ini dianggap tidak dapat untuk diaplikasikan pada keadaan sehari-hari. Seandainya para ilmuwan dapat memecahkan masalah ini maka risiko keamanan pada batera jenis lithium akan sangat berkurang.

\subsection{SolidWork}

Solidworks adalah salah satu software yang digunakan untuk merancang part permesinan atau susunan part pemesinan yang berupa assembling dengan tampilan $3 \mathrm{~d}$ untuk mempresentasikan part sebelum real partnya dibuat atau tampilan 2D(drawing) untuk gambar proses pemesinan, SolidWork model terdiri dari beberapa bagian yaitu :

Part adalah sebuah objek 3D yang tebentuk dari beberapa fitur. Sebuah part dapat menjadi sebuah komponen pada suatu asselmbly, dan hanya biasa juga digambarkan dalam bentuk 2D pada sebuah drawing. Fitur adalah bentukan :

1. Operasi-operasi yang membentuk Part. Base Feature adalah fitur yang pertama kali dibuat Ekstensi File SolidWork adalah SLDPRT.

2. Assembly adalah sebuah dokumen dimana part, feature dan assembly lain (Sub Assembly) disatukan bersama. Ekstensi file untuk SolidWork Assembly adalah SLDASM.

3. Drawing adalah gambaran 2D dari sebuah 3D part maupun assembly, ekstensi File untuk Solidwork Drawing adalah SLDDRW. 
Untuk permodelan pada industri pengecoran logam dalam hal pembuatan pattern nya, program program 3D seperti ini sangat membantu sebab akan memudahkan operator pattern untuk menterjemahkan gambar menjadi pattern /model casting pengecoran logam dan tentunya akan mengurangi kesalahan pembacaan gambar yang bisa mengakibatkan salah bentuk. Untuk industri permesinan selain dihasilkan gambar kerja untuk pengerjaan mesin manual juga hasil geometri dari SolidWorks ini bisa langsung diproses lagi dengan CAM program semisal MASTERCAM, SOLLIDCAM, VISUALMILL dll.

\subsection{Perangkat Lunak (Arduino IDE)}

Arduino diciptakan untuk para pemula bahkan yang tidak memiliki basic bahasa pemrograman sama sekali karena menggunakan bahasa $\mathrm{C}++$ yang telah dipermudah melalui library. Arduino menggunakan Software Processing yang digunakan untuk menulis program kedalam Arduino. Processing sendiri merupakan penggabungan antara bahasa $\mathrm{C}++$ dan Java. Software Arduino ini dapat di-install di berbagai operating system (OS) seperti: LINUX, Mac OS, Windows. Software IDE Arduino terdiri dari 3 (tiga) bagian:

1. Editor program, untuk menulis dan mengedit program dalam bahasa processing. Listing program pada Arduino disebut sketch.

2. Compiler, modul yang berfungsi mengubah bahasa processing (kode program) kedalam kode biner karena kode biner adalah satu-satunya bahasa program yang dipahami oleh mikrocontroller.

3. Uploader, modul yang berfungsi memasukkan kode biner kedalam memori microcontroller.

Struktur perintah pada arduino secara garis besar terdiri dari 2 (dua) bagian yaitu void setup dan void loop. Void setup berisi perintah yang akan dieksekusi hanya satu kali sejak arduino dihidupkan sedangkan void loop berisi perintah yang akan dieksekusi berulang-ulang selama arduino dinyalakan. Merupakan module driver motor DC yang paling banyak digunakan atau dipakai di dunia elektronika yang difungsikan untuk mengontrol kecepatan serta arah perputaran motor DC.

\section{METODE PENELITIAN}

Waktu dan Tempat Penulis melakukan penelitian di halaman Kampus Universitas Balikpapan Waktu Penelitian dilaksanakan mulai 01 April sampai dengan 20 Agustus 2019.

\section{Diagram Alir Penelitian}

Diagram penelitian disusun berdasarkan proses jalannya penelitian mulai dari persiapan penelitian, kajian literature, instrument penelitian, pengumpulan data hingga pada penyusunan laporan termasuk persiapan perancangan alat. Didalam alir penelitian dimulai dengan studi literature untuk mengumpulkan materi-materi berkaitan dengan penelitian yang akan dilakukan. Dengan studi literatur yang telah dikumpulkan maka penulis selanjutnya mempelajari konsep dasar dari penelitian yang akan dilakukan dan dilakukan juga dengan instrument data pendukung termasuk alat dan peralatan. Pengumpulan data pendukung diperlukan untuk mengumpulkan data pendukung pada alat peralatan yang akan digunakan pada rangkaian.

Setalah data yang digunakan telah siap, penulis masuk kedalam sesi perancangan alat dan instalasi alat. Bentuk diagram alir penelitian sebagai berikut :

Diagram alir penelitian dapat ditunjukkan dalam gambar 1 agar memermudah pemahaman penelitian

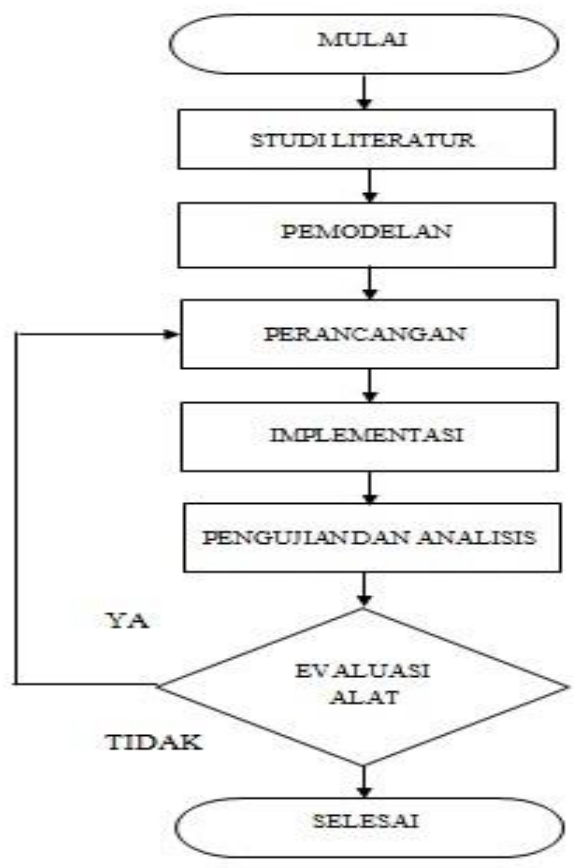

Gambar 1 . Diagram Penelitian

\section{Diagram Alir Perancangan Alat}

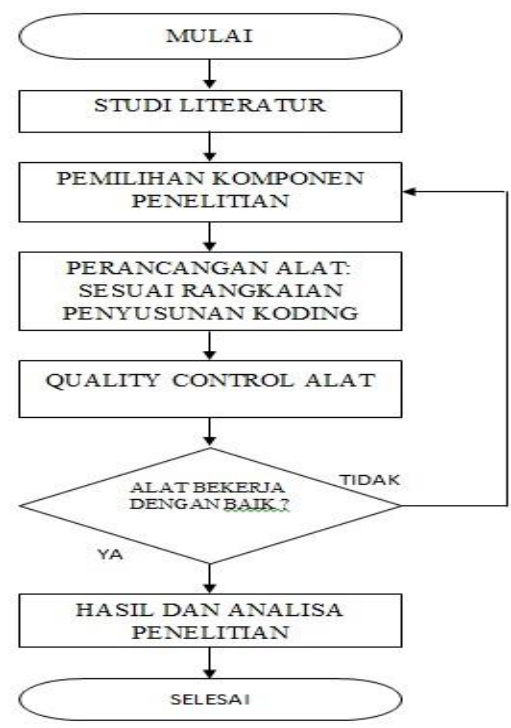

Gambar 2 Diagram Alir Perancangan. 
Didalam gambar 2 perancangan tersebut terlihat alur perancangan alat penelitian. Didalam perancangan awal dilakukan pemilihan komponen dan dilakukan perancangan alat yaitu menentukan skema rangkaian dan penyusunan koding setelah perancangan alat selesai maka dilakukan quality qontrol untuk mengetahui apakah alat berjalan dengan baik atau tidak, jika alat tidak berjalan dengan baik maka dilaukukan pemeriksaan komponen ulang untuk memastikan komponen mana yang tidak sesuai dan jika alat berjalan dengan baik maka proses hasil analisis dan penelitian telah selesai.

\section{III.METODE PENELITIAN}

Adapu metode penelitian dari di perihatkan pada blog diagram di bawah ini

\section{Blok Diagram}

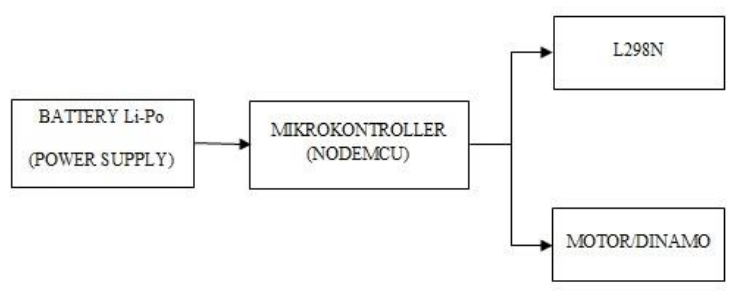

Gambar 3 Perancangan Alat Keseluruhan

\section{Flowchart}

Flowchart merupakan urutan-urutan langkah kerja proses yang digambarkan dengan menggunakan simbol-simbol yang disusun secara sistematis. Tujuan dari membuat flowchart adalah menggambarkan suatu tahapan penyelesaian masalah secara sederhana, terurai, rapi, jelas dan menggunakan simbol-simbol standar. Fungsinya memberikan gambaran secara garis besar untuk program atau aplikasi yang akan dibuat. Dengan demikian berikut merupakan Flowchart dari alat Mesin Pembersih Kabel Transmisi Listrik Berbasis Iternet :

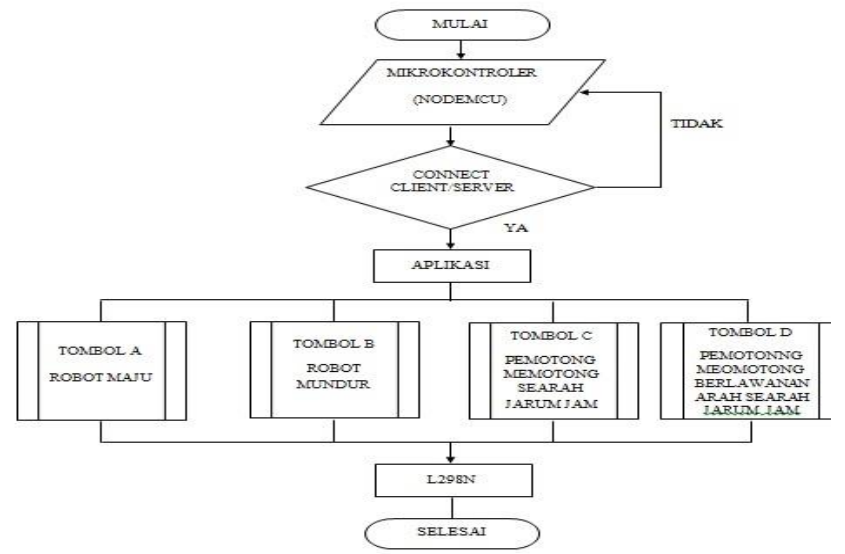

Gambar 4 Rancangan Aliran Proses

\section{Perancangan NodeMCU dengan L298N Dan Motor Driver}

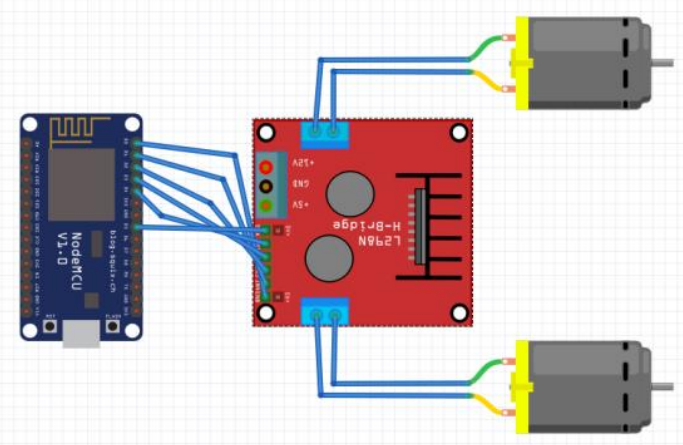

Gambar 5 Rancangan Bangun NodeMCU dengan L298N

Pin ENA, N1, N2, N3, N4, ENB L298N disambungkan ke pin D0, D1, D2, D3, D4, D5 pada NodeMCU sebagai pengatur nilai analog kecepatan motor DC.

\section{METODE PENELITIAN}

\section{Rangkaian Alat}

Adapun perancangan alat berdasarkan prototype yang dibuat pada Perancangan Prototype Mesin Pembersih Kabel Transmisi Listrik Berbasis Internet, berikut merupakan tampilan dari rangkaian alat :

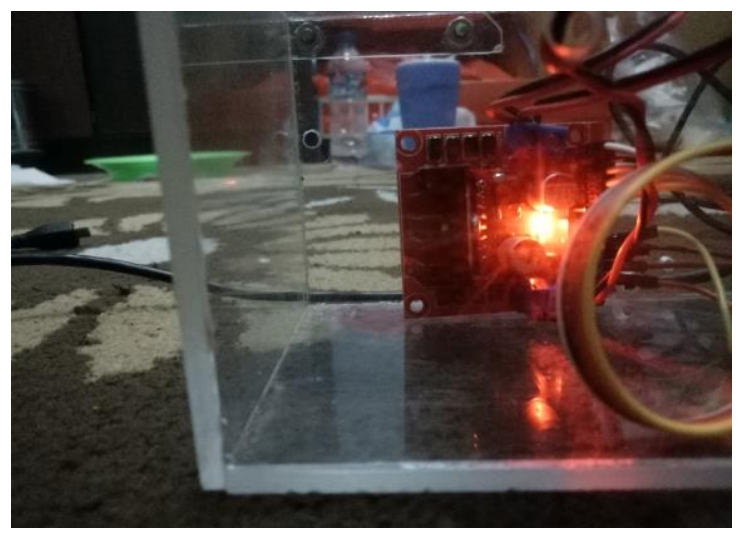

Gambar 6 Tampilan Motor Driver L298N

Fungsi dari Motor Driver L298N untuk dapat menggerakan Motor DC (Dinamo), apabila Motor DC dan Motor L298N telah terhubung maka Motor DC dapat digerakkan dengan sesuai keinginan pengguna. 
Tabel 1 Pengujian Blackbox

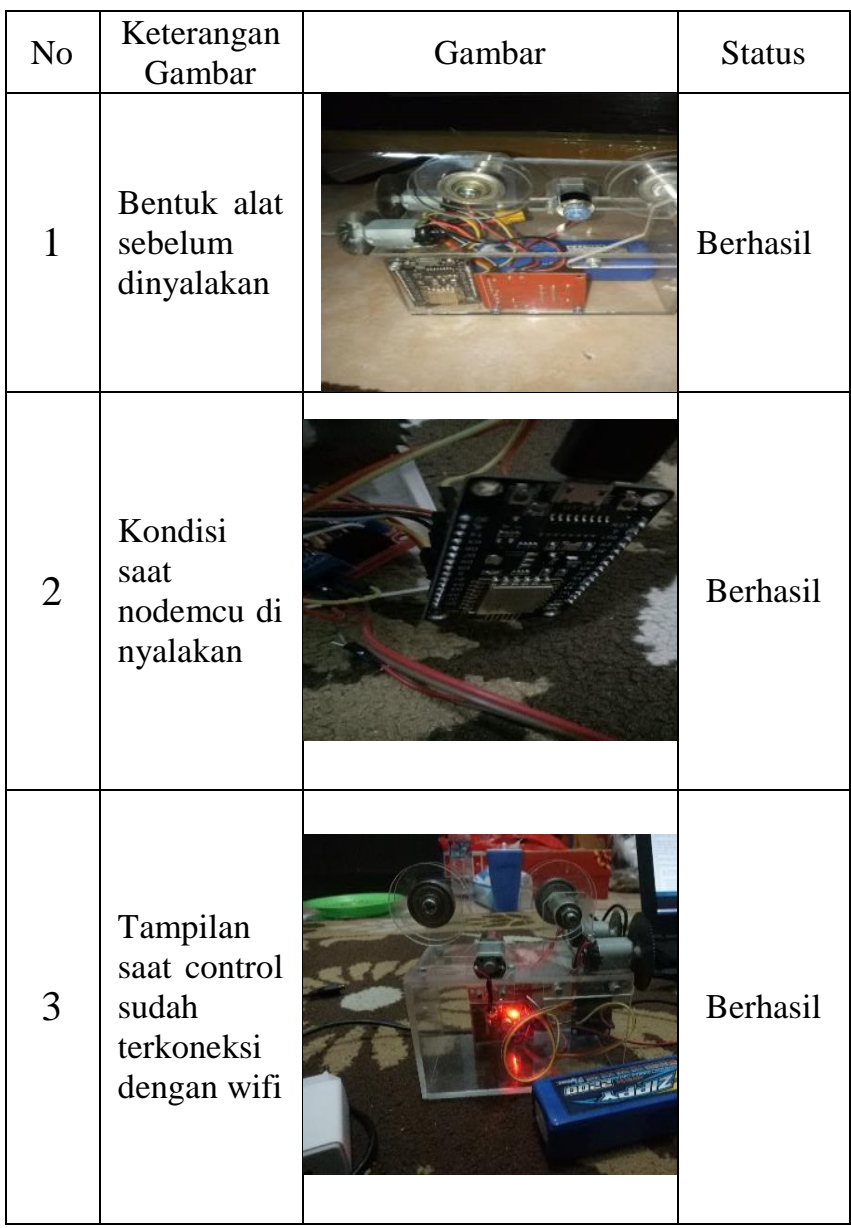

Tabel .2 Hasil Pengujian Driver Motor L298N

\begin{tabular}{|c|c|c|c|c|c|c|c|c|}
\hline \multirow{2}{*}{ Inputan } & \multicolumn{6}{|c|}{ Logika L298N } & \multirow{2}{*}{$\begin{array}{l}\text { Hasil } \\
\text { Serial } \\
\text { Monit } \\
\text { or }\end{array}$} & \multirow{2}{*}{ Ouput } \\
\hline & ENA & RM1 & $\begin{array}{c}\mathrm{RM} \\
2\end{array}$ & ENB & LM1 & LM2 & & \\
\hline Maju & 250 & LOW & $\begin{array}{c}\mathrm{HIG} \\
\mathrm{H}\end{array}$ & 250 & HIGH & LOW & ' 1 ' & $\begin{array}{c}\text { Bergerak } \\
\text { maju }\end{array}$ \\
\hline Mundur & 250 & $\mathrm{HIGH}$ & $\begin{array}{l}\text { LO } \\
\text { w }\end{array}$ & 250 & LOW & HIGH & ' 0 ' & $\begin{array}{l}\text { Bergerak } \\
\text { mundur }\end{array}$ \\
\hline Kanan & 250 & $\mathrm{HIGH}$ & $\begin{array}{l}\text { LO } \\
\mathrm{w}\end{array}$ & 250 & HIGH & LOW & ' 1 ' & $\begin{array}{c}\text { Memotong } \\
\text { Searah } \\
\text { Jarum Jam }\end{array}$ \\
\hline Kiri & 250 & HIGH & $\begin{array}{l}\text { LO } \\
\mathrm{w}\end{array}$ & 250 & HIGH & LOW & ' 0 ' & $\begin{array}{c}\text { Memotong } \\
\text { Berlawana } \\
\text { n searah } \\
\text { janum jam }\end{array}$ \\
\hline
\end{tabular}

Tabel 3 Hasil Pengujian Konektivitas Aplikasi Ke Jaringan Internet

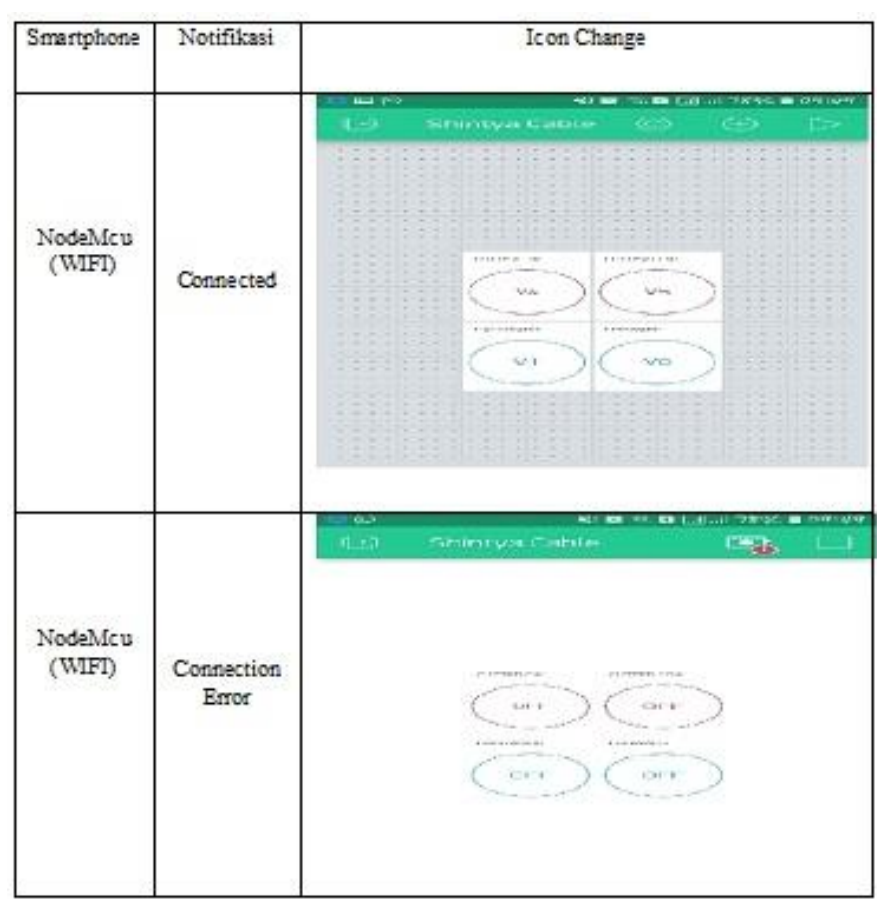

Tabel 4 Hasil Pengujian Alat

\begin{tabular}{|c|c|c|}
\hline \multicolumn{3}{|c|}{ U COBA ALAT } \\
\hline No & PENGUIIAN & HASIL \\
\hline \multicolumn{3}{|c|}{ UJI PERGERAKAN 1} \\
\hline 1. & MAJU & 1 \\
\hline 2. & MAJUSTOP & 1 \\
\hline 3. & MAJUSTOP MAJU & 1 \\
\hline & & $100 \%$ \\
\hline \multicolumn{3}{|c|}{ UII PERGERAKAN 2} \\
\hline 4. & MUNDUR & 1 \\
\hline 5. & MUNDURSTOP & 1 \\
\hline 6. & MUNDUR STOP MUNDUR & 1 \\
\hline & & $100 \%$ \\
\hline \multicolumn{3}{|c|}{ UI PEMOTONG 1} \\
\hline 7. & PEMOTONG MEMUTAR SEARAHJARUM JAM & 1 \\
\hline 8. & PEMOTONG MEMUTAR BERLAWAN ANSEARAH JARUM JAM & 1 \\
\hline & & $100 \%$ \\
\hline \multicolumn{3}{|c|}{ UII PEMOTONG 2} \\
\hline 9. & MEMOTONG BENANG JAHIT & 1 \\
\hline 10. & MEMOTONG BENANG GODAM & 0 \\
\hline 11. & MEMOTONG BENANG GELASAN & 1 \\
\hline 12. & MEMOTONG TALIRAPIA & 1 \\
\hline 13. & MEMOTONG RANTING POHON & 0 \\
\hline & $60 \%$ \\
\hline
\end{tabular}

\begin{tabular}{|c|l|r|}
\hline NO. & \multicolumn{1}{|c|}{ TINGKAT KEBERHASILAN UII COBA } & HASIL \\
\hline 1. & UII PERGERAKAN 1 & $100 \%$ \\
\hline 2. & UII PERGERAKAN 2 & $100 \%$ \\
\hline 3. & UII PEMOTONG 1 & $100 \%$ \\
\hline 4. & UII PEMOTONG 2 & $60 \%$ \\
\hline
\end{tabular}




\section{Proses Koneksi Robot Ke Smartphone}

Cara mengaktifkan Wifi di aplikasi Blynk untuk terhubung ke Robot tersebut:

1. Klik aplikasi Blynk

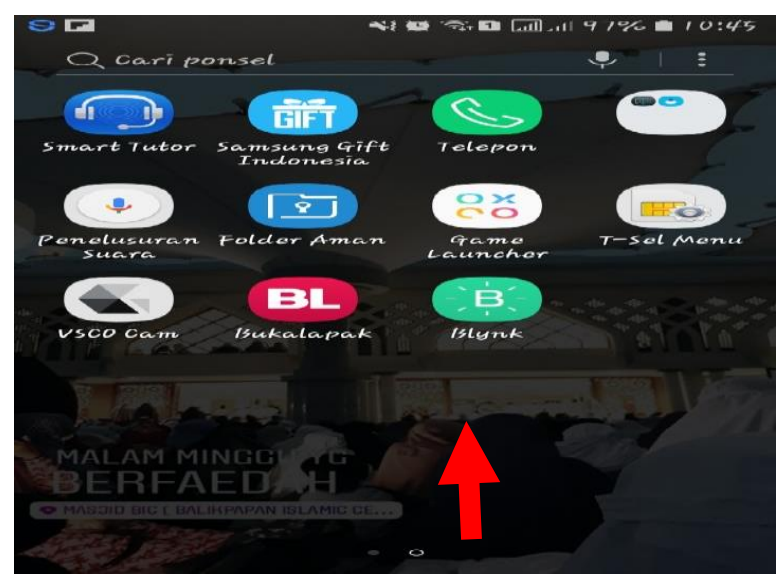

Gambar 7 Aplikasi Blynk

2. Pilih wifi yang akan di hubungkan

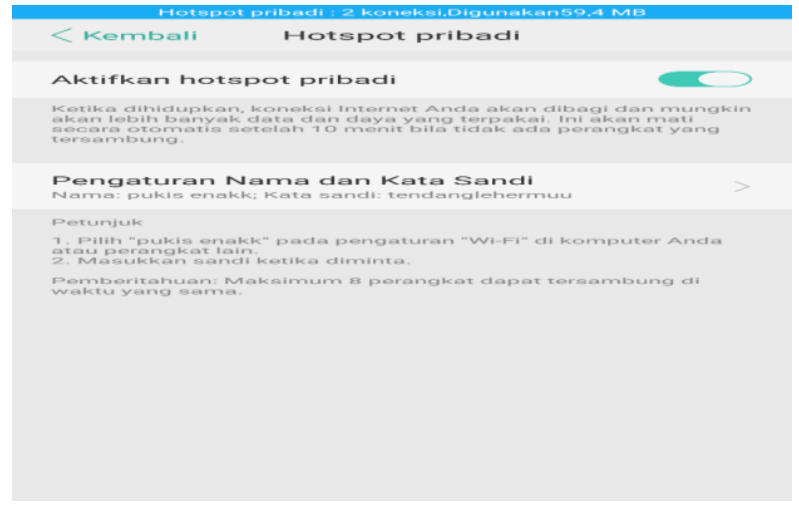

Gambar 8 Wifi Dihubungkan

3. Robot sudah bisa difungsikan dengan controller yang terdapat di aplikasi.
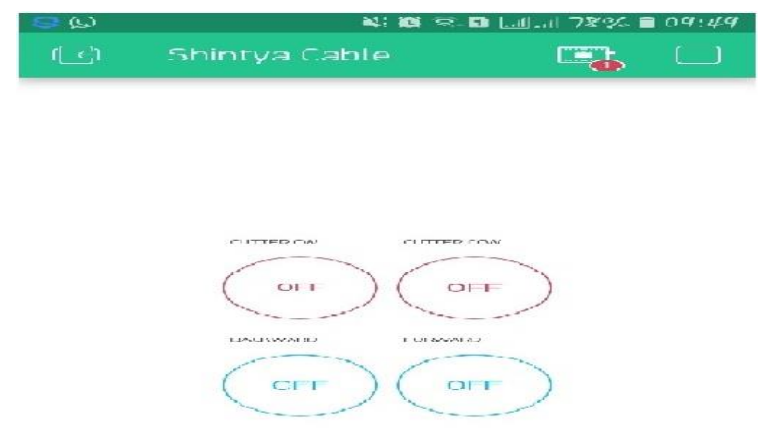

Gambar 9 Aplikasi Blynk

\section{PENUTUP}

Kesimpulan

Dari hasil pengujian alat tersebut dapat disimpulkan sebagai berikut :

1. Berhasil $100 \%$

- Uji Pergerakan 1 : Bergerak Maju, Maju Stop, dan Maju Stop Maju.

- Uji Pergerakan 2 : Bergerak Mundur, Mundur Stop, dan Mundur Stop Mundur

- Uji Pemotong 1 : Pemotong memutar searah jarum jam dan Pemotong memutar berlawanan arah searah jarum jam.

2. Hanya mampu $60 \%$

- Uji Pemotong 2 : Hanya benda - benda tertentu yang dapat memotong seperti benang jahit, benang gelasan dan tali rapia.

\section{VI.DAFTAR PUSAKA}

[1] N. Lestari, "PEMANFAATAN JARINGAN WIRELESS SEBAGAI PENGENDALI ROBOT," vol. V, no. 2, pp. 41-54, 2016.

[2] S. Samsugi and D. Kastutara, "INTERNET OF THINGS ( IOT ): Sistem Kendali Jarak Jauh Berbasis Arduino Dan Modul Wifi Esp8266,” 2017.

[3] E. Saputro, "Rancang Bangun Pengaman Pintu Otomatis Menggunakan E-KTP Berbasis Mikrokontroler Atmega328," J. Tek. Elektro, vol. 8, no. 1, pp. 1-4, 2016.

[4] B. P. Lapanporo, Hengki, and Nurhasanah, "Prototipe Sistem Telemetri Tinggi Muka Air dan Kontrol Pintu Air Otomatis," vol. V, no. 1, pp. 37-40, 2017.

[5] J. T. Elektro et al., "ROBOT PEMBERSIH LANTAI BERBASIS ARDUINO UNO DENGAN SENSOR," vol. 6, no. 3, pp. 136-143, 2015.

[6] Santosa, H, 2012, Apa itu Arduino, http://hardisantosa.blog.ugm.ac.id /2012/06/23/apa-itu-arduino/, 07 Januari 2015, 11.00 WIB.

[7] Sulaiman, Arif 2012. ARDUINO : Mikrocontroller bagi Pemula hingga Mahir.

[8] A. Faudin, "utorial Arduino mengakses driver motor L298N." 2017. 